\title{
Prevalence of Depressive Symptoms and Related Factors in Japanese Employees: A Comparative Study between Surveys from 2007 and 2010
}

\author{
Masahito Fushimi ${ }^{1,2}$ \\ ${ }^{1}$ Akita Prefectural Mental Health and Welfare Center, 2-1-51 Nakadori, Akita City, Akita Prefecture 010-0001, Japan \\ ${ }^{2}$ Akita Occupational Health Promotion Center, 6-6 Senshukubota-machi, Akita City, Akita Prefecture 010-0874, Japan \\ Correspondence should be addressed to Masahito Fushimi; fushimi@sings.jp
}

Received 18 May 2015; Revised 3 July 2015; Accepted 5 July 2015

Academic Editor: Nicola Magnavita

Copyright (C) 2015 Masahito Fushimi. This is an open access article distributed under the Creative Commons Attribution License, which permits unrestricted use, distribution, and reproduction in any medium, provided the original work is properly cited.

\begin{abstract}
Aims. The aim of this study was to examine the prevalence of depressive symptoms and their related factors in Japan. The results were analyzed to identify the relationship between high scores on the CES-D, sociodemographic status, and employment-related variables. Methods. Employees in Akita prefecture completed the Center for Epidemiologic Studies Depression Scale (CES-D) during a survey period between November and December 2010. The cutoff point for the CES-D scores was 16 or above (high scorers). Results. Data from 1,476 employees indicated that $44.2 \%$ had high scores on the CES-D. Sociodemographic and occupation-related factors associated with a high risk of depression were being female, young age, fewer hours of sleep on weekdays, and working over 8 hours per day, whereas drinking alcohol one to two days per week, albeit only in men, was significantly associated with a low risk of depression. The present results were consistent with the results of a previous survey completed in 2007; however, the present results regarding job categories and smoking behavior were not significantly associated with depression and thus were inconsistent with the 2007 survey data. Conclusions. These results can be useful as benchmark values for the CES-D and might help predict depressive disorders.
\end{abstract}

\section{Introduction}

The suicide rate in Japan steadily increased during the 1990s and sharply escalated in 1998. The main factor contributing to this surge was the sudden increase in suicide rates among middle-aged men (i.e., working age), often considered to be related to the drastic social changes occurring around that time, such as the national economic crisis (Japan's recession) and the termination of lifetime employment practices by many major companies. Currently, Japan has one of the highest suicide rates among developed countries, making suicide an important national problem. Health problems are regarded as the cause of the majority of the reported suicides in Japan [1]. It is important that occupational safety and health programs adopt an approach that is built on proactive prevention, screening, and early intervention, as well as the notion that mental health problems among employees are associated with a decline in employee productivity-thus, effective interventions alleviate mental health symptoms, thereby increasing employee productivity [2-4]. Depressive disorder is one of the most common mental disorders and is a major public health problem in Japan [1]. Previous surveys on the prevalence of depression and depressive symptoms in Japan have yielded widely different results $[5,6]$. Occupational safety and health programs typically invite employees to complete a voluntary health assessment questionnaire at their workplace, involving brief self-report health scales (i.e., nondiagnostic methods), to determine the prevalence and severity of depressive symptoms. The Center for Epidemiologic Studies Depression Scale (CESD), a self-report depression scale, has been widely used in population surveys across the world and has satisfactory levels of reliability and validity in numerous cultures [7, 8]. The CES-D has been translated into Japanese, and its reliability and validity have been confirmed in the Japanese general population $[9,10]$. In the present study, a universal cutoff point of 16 was employed, since it most effectively detects and covers "probable" depression symptoms [5]. 
In this study, the prevalence of depressive symptoms using the CES-D among a probability sample of Japanese employees in Akita prefecture was examined. In addition, the predictors of these symptoms were analyzed. We had previously conducted an occupational mental health study in 2007 [11]. The present study, conducted in 2010, is a followup study that adopted similar methods to the 2007 study. In this report, the results of these two studies are compared, and these results can be used as benchmarks for comparisons of future employee health-risk assessment surveys using the CES-D. The data presented in this paper will help identify employees at high risk of depressive disorders and detect the contributing sociodemographic and work-related factors.

\section{Materials and Methods}

2.1. Participants. The information presented in this report was collected as part of the Northern-Japan Occupational Health Promotion Centers Collaboration Study for Mental Health (NOCS-MH), conducted by the occupational health promotion centers located in the seven prefectures of northern Japan (Hokkaido, Aomori, Iwate, Miyagi, Akita, Yamagata, and Fukushima). The NOCS-MH investigates stress situations and stress management skills and assesses depressive symptoms in employees [11]. The information from the Akita region was taken from the NOCS-MH. Participants were recruited first by randomly selecting their employers (random systematic sampling) and then by encouraging the employers to ask their employees to answer the survey. The companies ("employers") requested in the 2007 surveywhich were selected by random systematic sampling-were asked to participate in this survey as well. Thus, requests in the 2010 survey were made to the same employers; however, since participation was voluntary, participant companies were not quite identical between the two surveys. The survey period was from November to December 2010. Twenty employers from Akita's public and private sectors agreed to participate in the study. Participation in the paper-based survey was voluntary and confidential. Of the 1,813 employees who were administered the questionnaire, 1,670 responded (a response rate of 92.1\%). The Japan Labour Health and Welfare Organization, which has occupational health promotion centers established in each administrative division, approved the study protocol.

2.2. Instruments and Analysis. To determine the prevalence and severity of depressive symptoms, the CES-D was used. Each of the 20 items on the CES-D is rated on a fourpoint scale ranging from "rarely or none of the time" (0) to "most or all of the time" (3) and refers to how often the respondent felt what the item described in the previous week. The sum of the response scores can range from 0 to 60. Calibration studies of the CES-D indicate that scores of 16 or above represent "probable" depression symptoms; therefore, a cutoff score of 16 indicates significant current depressive symptomatology [5]. Sociodemographic information, including sex, age, which was divided into groups of 29 years and below, 30 to 39 years, 40 to 49 years, and 50 years and above, and highest level of education obtained (compulsory and senior high school, tertiary education, and graduate degree or higher), was also collected. Additionally, the questionnaire collected information about the employees' occupational characteristics (full-time work, managerial class, and job category). The employees had to choose one of the following job categories: clerical or administrative support (e.g., administrative assistant, office supervisor), professional (e.g., engineer, doctor, and nurse), sales- or service-related occupation (e.g., sales representative, retail sales staff), technical support (e.g., laboratory technician, computer programmer), and others (e.g., on-site worker, driver). The survey included items on the average number of working hours per day ( $\leq 8$ and $>8 \mathrm{~h}$ ). In the present study, participants were also asked about their sleep duration per day, which was then sorted by hours of sleep per day during the weekdays $(<6,6,7$, and $>7 \mathrm{~h})$ and hours per day on holidays $(<6,6,7,8$, and $>8 \mathrm{~h})$. In our previous 2007 study, questions regarding sleep were not categorized this way [11]. The survey also included items on the smoking behavior (nonsmoker, ceased smoker, and current smoker). In the present study, alcohol consumption was measured by days of consumption per week (none/rare, 1-2 days/week, 3-5 days/week, and 6-7 days/week); these items were more detailed than those used in the 2007 study (i.e., none/rare, sometimes, and daily consumption) [11].

Statistical analyses took the form of cross tabulations of the prevalence of depressive symptoms versus sociodemographic and employment variables, performed using SPSS version 11.0J for Windows (SPSS, Tokyo, Japan). Statistical differences were measured using three binomial multivariate logistic regressions with CES-D score $(<16$ or $\geq 16)$ as the dependent variable. Sex was included as an independent variable in one regression. The remaining two had separate data sets for men and women.

\section{Results}

The number of effective respondents, excluding those with insufficient data, was 1,476 (81.4\%), including 883 men and 593 women. Table 1 presents the numbers, means, and standard deviations of the CES-D by sex and age. The mean score for the CES-D for all respondents was $16.12(\mathrm{SD}=9.23$; mean $=15.29$ and $\mathrm{SD}=8.66$ for men; mean $=17.37$ and $\mathrm{SD}=9.90$ for women), with lower mean scores among men than among women in all age groups. Table 2 distinguishes employees with a CES-D score of 16 or above (high scorers) from the others (low scorers). It also presents the sociodemographic status and employment-related variables and shows the percentages of high scorers on the CES-D by the demographics of each category. The overall prevalence of high scorers on the CES-D was $44.2 \%$ (41.1\% for men, $48.7 \%$ for women), with a lower prevalence of high scorers among men than among women in all age groups. Further, a lower prevalence of high scorers was observed in the older age groups.

Table 3 shows the adjusted odds ratios (OR) from the binomial multivariate logistic regression for high scorers on the CES-D (16 or above) by sociodemographic status and employment-related variables. It indicates that the independent effect of sex on the prevalence of high scorers was 
TABLE 1: Numbers, mean scores, and standard deviations of the CES-D scores according to sex and age in the 2010 survey.

\begin{tabular}{|c|c|c|c|c|c|c|c|c|c|}
\hline \multirow{2}{*}{ Age } & \multicolumn{3}{|c|}{ Total } & \multicolumn{3}{|c|}{ Men } & \multicolumn{3}{|c|}{ Women } \\
\hline & Number & Mean & $\mathrm{SD}$ & Number & Mean & $\mathrm{SD}$ & Number & Mean & SD \\
\hline$\leq 29$ & 291 & 19.02 & 10.46 & 174 & 17.16 & 8.77 & 117 & 21.80 & 12.07 \\
\hline $30-39$ & 396 & 15.82 & 8.44 & 255 & 15.47 & 8.38 & 141 & 16.45 & 8.54 \\
\hline $40-49$ & 394 & 15.89 & 9.29 & 229 & 15.23 & 9.29 & 165 & 16.80 & 9.25 \\
\hline$\geq 50$ & 395 & 14.51 & 8.49 & 225 & 13.68 & 7.93 & 170 & 15.62 & 9.08 \\
\hline Total & 1476 & 16.12 & 9.23 & 883 & 15.29 & 8.66 & 593 & 17.37 & 9.90 \\
\hline
\end{tabular}

significant. Namely, being female was significantly associated with a greater likelihood of being a high scorer. Among women, the prevalence of high scorers varied significantly by age (" 50 years or above" had the lowest OR) and sleep duration on weekdays (" $6 \mathrm{~h}$ " was associated with a decreased OR). However, these associations were not observed for men. In contrast, for men, the prevalence of high scorers on the CES-D varied significantly by sleep duration on weekdays ("7 h" was associated with a decreased OR) and alcohol consumption ("1-2 days/week" was associated with a decreased OR). On average, among men and women, participants aged "50 years or above" had the lowest likelihood of being high scorers; working more than eight hours per day was significantly associated with an increased likelihood; and those who selected six and seven hours of sleep on weekdays had significantly lower likelihoods of being high scorers.

\section{Discussion}

In the present study, the mean CES-D score was 16.12, and $44.2 \%$ of employees exhibited high CES-D scores (16 or above). These results were similar to our previous findings in 2007 (16.09 and 45.0\%, resp.). Several studies using the CES-D, in Japan and abroad, showed mean CES-D scores of approximately $5-10$, with prevalence rates of high CES-D scorers (also using the cutoff point of 16) ranging from 10\% to $20 \%[9,11-13]$. The mean CES-D score and the prevalence rate of high scorers in this study are higher than the findings of previous studies. Our results clearly show that employers and managers cannot assume that their employees are free from mental health problems and suggest that screening and early intervention for problems such as depression might be an appropriate course of action. To prevent the negative consequences of mental health problems in the workplace, including high absenteeism, low productivity, and employee attrition, employers need to invest in mental health resources. Previous studies suggest that case management programs for employees with mental health problems lead to superior clinical outcomes, decreased unemployment, and increased employee productivity. Therefore, such programs have the potential to provide the employer with positive returns on their investment $[2-4,14]$. It is unclear why so many respondents in the present study scored high on the CES-D. This might be partly explained by drastic social changes in job opportunities or the work environment and by a culturally different response styles to certain questions (e.g., Japanese are reluctant to express their positive affect) $[1,5,9,10,15,16]$. Further studies are required to clarify this point.
In this study, the adjusted OR from the binomial multivariate logistic regression for high scorers on the CES$\mathrm{D}$ also showed that the prevalence of high scorers on the CES-D varied significantly by sex, age, working hours, sleep duration on weekdays, and alcohol consumption, whereas it did not vary significantly by job category, sleep duration on holidays, and smoking behavior. In contrast, our previous results showed that the prevalence of high scorers on the CES$\mathrm{D}$ varied significantly by job category and smoking behavior [11]. Therefore, sex, age, daily working hours, sleep durations, and alcohol consumption may be highly reproducible variables that predict CES-D score, whereas job category and smoking behavior may be insufficiently reproducible. Furthermore, it can be said that dividing sleep durations by weekdays and holidays is meaningful.

Previous studies using the CES-D scale have reported that gender, young age, and low educational level are independent risk factors for depressive symptoms $[5,7,17-20]$, and the results of our study supported these findings to some extent. However, educational level was not significantly associated with high scores on the CES-D. Previous reports are inconsistent in terms of the relationship between depressive symptoms and educational levels $[15,16]$. It has been widely accepted that as educational level decreases, the prevalence of mental health problems increases [5]. However, according to another report, significantly high levels of psychological distress were noted among employees with a postgraduate degree [21].

In this study, job category was not significantly associated with the prevalence rates of high scorers on the CES-D. However, in our previous study [11], job category was significantly associated with the prevalence rates (i.e., women in professional roles were highly likely to be high scorers on the CES-D). Therefore, it is believed that these results may not be reproducible. In several previous studies, lower rates of depressive symptoms were found among those who were highly educated and employed in professional/managerial positions. People in these groups seem to have less difficulty adjusting to changes in the social environment and controlling work-related distress [5]. In brief, there is no consistent evidence of the relationship between job category and psychological distress in the previous literature, no doubt due to the complexity of the relationship [16, 22].

Another indicator of psychological distress was hours spent working. Generally, high work demand is associated with a decline in mental well-being $[23,24]$ as is the pressure to work overtime. Increased working hours might also produce a negative work-to-family spillover, which is 
TABLE 2: Demographics of sample and the comparison between nonhigh scorers on the CES-D $(<16)$ and high scorers on the CES-D $(\geq 16)$ in the 2010 survey.

\begin{tabular}{|c|c|c|c|c|c|c|c|c|c|c|c|c|c|c|c|}
\hline & \multicolumn{6}{|c|}{ Nonhigh scorers on the CES-D $(<16)$} & \multicolumn{6}{|c|}{ High scorers on the CES-D $(\geq 16)$} & \multicolumn{3}{|c|}{$\begin{array}{c}\% \text { of high scorers } \\
\text { on the CES-D }\end{array}$} \\
\hline & \multicolumn{3}{|c|}{ Number } & \multicolumn{3}{|c|}{$\%$ of each category } & \multicolumn{3}{|c|}{ Number } & \multicolumn{3}{|c|}{$\%$ of each category } & & & \\
\hline & Total & Men & Women & Total & Men & Women & Total & Men & Women & Total & 1 Men & Women & Total & Men & Women \\
\hline Sex & 824 & 520 & 304 & 100 & 63.1 & 36.9 & 652 & 363 & 289 & 100 & 55.7 & 44.3 & 44.2 & 41.1 & 48.7 \\
\hline \multicolumn{16}{|l|}{ Age } \\
\hline$\leq 29$ & 130 & 87 & 43 & 15.8 & 16.7 & 14.1 & 161 & 87 & 74 & 24.7 & 24.0 & 25.6 & 55.3 & 50.0 & 63.2 \\
\hline $30-39$ & 220 & 147 & 73 & 26.7 & 28.3 & 24.0 & 176 & 108 & 68 & 27.0 & 29.8 & 23.5 & 44.4 & 42.4 & 48.2 \\
\hline $40-49$ & 222 & 136 & 86 & 26.9 & 26.2 & 28.3 & 172 & 93 & 79 & 26.4 & 25.6 & 27.3 & 43.7 & 40.6 & 47.9 \\
\hline$\geq 50$ & 252 & 150 & 102 & 30.6 & 28.8 & 33.6 & 143 & 75 & 68 & 21.9 & 20.7 & 23.5 & 36.2 & 33.3 & 40.0 \\
\hline \multicolumn{16}{|l|}{ Education } \\
\hline Compulsory/senior high school & 491 & 331 & 160 & 59.6 & 63.7 & 52.6 & 375 & 237 & 138 & 57.5 & 65.3 & 47.8 & 43.3 & 41.7 & 46.3 \\
\hline Some tertiary education & 194 & 82 & 112 & 23.5 & 15.8 & 36.8 & 177 & 64 & 113 & 27.1 & 17.6 & 39.1 & 47.7 & 43.8 & 50.2 \\
\hline Graduate degree or higher & 137 & 106 & 31 & 16.6 & 20.4 & 10.2 & 98 & 60 & 38 & 15.0 & 16.5 & 13.1 & 41.7 & 36.1 & 55.1 \\
\hline \multicolumn{16}{|l|}{ Employment status } \\
\hline Full-time work & 667 & 451 & 216 & 80.9 & 86.7 & 71.1 & 555 & 331 & 224 & 85.1 & 91.2 & 77.5 & 45.4 & 42.3 & 50.9 \\
\hline No full-time work & 94 & 31 & 63 & 11.4 & 6.0 & 20.7 & 58 & 16 & 42 & 8.9 & 4.4 & 14.5 & 38.2 & 34.0 & 40.0 \\
\hline \multicolumn{16}{|l|}{ Employee type } \\
\hline Nonmanagerial class & 570 & 326 & 244 & 69.2 & 62.7 & 80.3 & 472 & 255 & 217 & 72.4 & 70.2 & 75.1 & 45.3 & 43.9 & 47.1 \\
\hline Managerial class & 160 & 126 & 34 & 19.4 & 24.2 & 11.2 & 106 & 65 & 41 & 16.3 & 17.9 & 14.2 & 39.8 & 34.0 & 54.7 \\
\hline \multicolumn{16}{|l|}{ Job category } \\
\hline Clerical/administrative & 195 & 110 & 85 & 23.7 & 21.2 & 28.0 & 136 & 67 & 69 & 20.9 & 18.5 & 23.9 & 41.1 & 37.9 & 44.8 \\
\hline Professional & 191 & 79 & 112 & 23.2 & 15.2 & 36.8 & 167 & 46 & 121 & 25.6 & 12.7 & 41.9 & 46.6 & 36.8 & 51.9 \\
\hline Sales/service & 64 & 50 & 14 & 7.8 & 9.6 & 4.6 & 43 & 32 & 11 & 6.6 & 8.8 & 3.8 & 40.2 & 39.0 & 44.0 \\
\hline Technical & 176 & 146 & 30 & 21.4 & 28.1 & 9.9 & 149 & 116 & 33 & 22.9 & 32.0 & 11.4 & 45.8 & 44.3 & 52.4 \\
\hline Others (on-site workers) & 184 & 126 & 58 & 22.3 & 24.2 & 19.1 & 143 & 92 & 51 & 21.9 & 25.3 & 17.6 & 43.7 & 42.2 & 46.8 \\
\hline \multicolumn{16}{|l|}{ Working hours per day } \\
\hline$\leq 8 \mathrm{~h}$ & 467 & 266 & 201 & 56.7 & 51.2 & 66.1 & 323 & 167 & 156 & 49.5 & 46.0 & 54.0 & 40.9 & 38.6 & 43.7 \\
\hline$>8 \mathrm{~h}$ & 350 & 250 & 100 & 42.5 & 48.1 & 32.9 & 327 & 195 & 132 & 50.2 & 53.7 & 45.7 & 48.3 & 43.8 & 56.9 \\
\hline \multicolumn{16}{|l|}{ Sleep duration (weekdays) } \\
\hline$<6 \mathrm{~h}$ & 105 & 56 & 49 & 12.7 & 10.8 & 16.1 & 172 & 84 & 88 & 26.4 & 23.1 & 30.4 & 62.1 & 60.0 & 64.2 \\
\hline $6 \mathrm{~h}$ & 332 & 190 & 142 & 40.3 & 36.5 & 46.7 & 241 & 146 & 95 & 37.0 & 40.2 & 32.9 & 42.1 & 43.5 & 40.1 \\
\hline $7 \mathrm{~h}$ & 257 & 182 & 75 & 31.2 & 35.0 & 24.7 & 154 & 83 & 71 & 23.6 & 22.9 & 24.6 & 37.5 & 31.3 & 48.6 \\
\hline$>7 \mathrm{~h}$ & 114 & 83 & 31 & 13.8 & 16.0 & 10.2 & 71 & 48 & 23 & 10.9 & 13.2 & 8.0 & 38.4 & 36.6 & 42.6 \\
\hline \multicolumn{16}{|l|}{ Sleep duration (holidays) } \\
\hline$<6 \mathrm{~h}$ & 30 & 19 & 11 & 3.6 & 3.7 & 3.6 & 55 & 31 & 24 & 8.4 & 8.5 & 8.3 & 64.7 & 62.0 & 68.6 \\
\hline $6 \mathrm{~h}$ & 148 & 97 & 51 & 18.0 & 18.7 & 16.8 & 118 & 61 & 57 & 18.1 & 16.8 & 19.7 & 44.4 & 38.6 & 52.8 \\
\hline $7 \mathrm{~h}$ & 183 & 114 & 69 & 22.2 & 21.9 & 22.7 & 126 & 76 & 50 & 19.3 & 20.9 & 17.3 & 40.8 & 40.0 & 42.0 \\
\hline $8 \mathrm{~h}$ & 194 & 132 & 62 & 23.5 & 25.4 & 20.4 & 129 & 78 & 51 & 19.8 & 21.5 & 17.6 & 39.9 & 37.1 & 45.1 \\
\hline$>8 \mathrm{~h}$ & 35 & 24 & 11 & 4.2 & 4.6 & 3.6 & 48 & 25 & 23 & 7.4 & 6.9 & 8.0 & 57.8 & 51.0 & 67.6 \\
\hline \multicolumn{16}{|l|}{ Smoking behavior } \\
\hline Nonsmoker & 331 & 112 & 219 & 40.2 & 21.5 & 72.0 & 268 & 81 & 187 & 41.1 & 22.3 & 64.7 & 44.7 & 42.0 & 46.1 \\
\hline Ceased smoker & 188 & 149 & 39 & 22.8 & 28.7 & 12.8 & 123 & 85 & 38 & 18.9 & 23.4 & 13.1 & 39.5 & 36.3 & 49.4 \\
\hline Current smoker & 302 & 259 & 43 & 36.7 & 49.8 & 14.1 & 260 & 197 & 63 & 39.9 & 54.3 & 21.8 & 46.3 & 43.2 & 59.4 \\
\hline \multicolumn{16}{|l|}{ Alcohol consumption } \\
\hline None/rare & 287 & 118 & 169 & 34.8 & 22.7 & 55.6 & 259 & 108 & 151 & 39.7 & 29.8 & 52.2 & 47.4 & 47.8 & 47.2 \\
\hline 1-2/week & 164 & 103 & 61 & 19.9 & 19.8 & 20.1 & 133 & 61 & 72 & 20.4 & 16.8 & 24.9 & 44.8 & 37.2 & 54.1 \\
\hline 3-5/week & 102 & 71 & 31 & 12.4 & 13.7 & 10.2 & 75 & 48 & 27 & 11.5 & 13.2 & 9.3 & 42.4 & 40.3 & 46.6 \\
\hline 6-7/week & 269 & 227 & 42 & 32.6 & 43.7 & 13.8 & 185 & 146 & 39 & 28.4 & 40.2 & 13.5 & 40.7 & 39.1 & 48.1 \\
\hline
\end{tabular}


TABLE 3: Effects of sociodemographic and employment-related factors on the prevalence of high scorers on the CES-D ( $\geq 16)$ in the 2010 survey.

\begin{tabular}{|c|c|c|c|c|c|c|c|c|c|}
\hline & \multicolumn{3}{|c|}{ Total } & \multicolumn{3}{|c|}{ Male } & \multicolumn{3}{|c|}{ Female } \\
\hline & OR & $95 \% \mathrm{CI}$ & $p$ value & OR & $95 \% \mathrm{CI}$ & $p$ value & OR & $95 \% \mathrm{CI}$ & $p$ value \\
\hline \multicolumn{10}{|l|}{ Sex } \\
\hline Men & & Ref. & & & & & & & \\
\hline Women & 1.49 & $1.03-2.15$ & $<0.05$ & & & & & & \\
\hline \multicolumn{10}{|l|}{ Age } \\
\hline$\leq 29$ & & Ref. & & & Ref. & & & Ref. & \\
\hline $30-39$ & 0.67 & $0.44-1.01$ & 0.06 & 0.90 & $0.54-1.52$ & 0.69 & 0.39 & $0.18-0.81$ & $<0.05$ \\
\hline $40-49$ & 0.72 & $0.46-1.11$ & 0.14 & 1.07 & $0.60-1.90$ & 0.81 & 0.39 & $0.19-0.83$ & $<0.05$ \\
\hline$\geq 50$ & 0.52 & $0.33-0.83$ & $<0.01$ & 0.70 & $0.37-1.34$ & 0.29 & 0.30 & $0.14-0.67$ & $<0.005$ \\
\hline \multicolumn{10}{|l|}{ Education } \\
\hline Compulsory/senior high school & & Ref. & & & Ref. & & & Ref. & \\
\hline Some tertiary education & 0.98 & $0.66-1.46$ & 0.93 & 1.02 & $0.60-1.73$ & 0.94 & 0.78 & $0.40-1.50$ & 0.45 \\
\hline Graduate degree or higher & 0.77 & $0.50-1.20$ & 0.25 & 0.77 & $0.45-1.31$ & 0.33 & 0.69 & $0.29-1.64$ & 0.40 \\
\hline \multicolumn{10}{|l|}{ Employment status } \\
\hline Full-time work & & Ref. & & & Ref. & & & Ref. & \\
\hline No full-time work & 0.80 & $0.50-1.30$ & 0.38 & 1.04 & $0.47-2.31$ & 0.92 & 0.88 & $0.44-1.74$ & 0.70 \\
\hline \multicolumn{10}{|l|}{ Employee type } \\
\hline Nonmanagerial class & & Ref. & & & Ref. & & & Ref. & \\
\hline Managerial class & 0.91 & $0.60-1.38$ & 0.65 & 0.64 & $0.38-1.07$ & 0.09 & 1.82 & $0.76-4.34$ & 0.18 \\
\hline \multicolumn{10}{|l|}{ Job category } \\
\hline Clerical/administrative & & Ref. & & & Ref. & & & Ref. & \\
\hline Professional & 0.73 & $0.47-1.12$ & 0.15 & 0.62 & $0.34-1.15$ & 0.13 & 0.81 & $0.41-1.60$ & 0.54 \\
\hline Sales/service & 1.08 & $0.57-2.07$ & 0.81 & 0.92 & $0.42-2.05$ & 0.85 & 1.36 & $0.36-5.09$ & 0.65 \\
\hline Technical & 0.76 & $0.48-1.20$ & 0.23 & 0.68 & $0.39-1.19$ & 0.18 & 0.83 & $0.33-2.12$ & 0.70 \\
\hline Others (on-site workers) & 0.92 & $0.57-1.47$ & 0.72 & 0.83 & $0.46-1.49$ & 0.52 & 0.82 & $0.34-1.98$ & 0.66 \\
\hline \multicolumn{10}{|l|}{ Working hours per day } \\
\hline$\leq 8 \mathrm{~h}$ & & Ref. & & & Ref. & & & Ref. & \\
\hline$>8 \mathrm{~h}$ & 1.42 & $1.04-1.94$ & $<0.05$ & 1.34 & $0.90-1.99$ & 0.15 & 1.63 & $0.94-2.81$ & 0.08 \\
\hline \multicolumn{10}{|l|}{ Sleep duration (weekdays) } \\
\hline$<6 \mathrm{~h}$ & & Ref. & & & Ref. & & & Ref. & \\
\hline $6 \mathrm{~h}$ & 0.56 & $0.37-0.86$ & $<0.01$ & 0.57 & $0.32-1.02$ & 0.06 & 0.51 & $0.26-0.97$ & $<0.05$ \\
\hline $7 \mathrm{~h}$ & 0.46 & $0.28-0.76$ & $<0.005$ & 0.34 & $0.17-0.67$ & $<0.005$ & 0.67 & $0.31-1.46$ & 0.32 \\
\hline$>7 \mathrm{~h}$ & 0.85 & $0.45-1.61$ & 0.61 & 0.61 & $0.27-1.39$ & 0.24 & 1.92 & $0.55-6.73$ & 0.31 \\
\hline \multicolumn{10}{|l|}{ Sleep duration (holidays) } \\
\hline$<6 \mathrm{~h}$ & & Ref. & & & & & & & \\
\hline $6 \mathrm{~h}$ & 0.72 & $0.37-1.40$ & 0.33 & 0.62 & $0.26-1.50$ & 0.29 & 1.11 & $0.37-3.31$ & 0.85 \\
\hline $7 \mathrm{~h}$ & 0.61 & $0.31-1.20$ & 0.15 & 0.72 & $0.29-1.75$ & 0.46 & 0.59 & $0.20-1.71$ & 0.33 \\
\hline $8 \mathrm{~h}$ & 0.55 & $0.27-1.09$ & 0.09 & 0.58 & $0.23-1.45$ & 0.24 & 0.57 & $0.18-1.75$ & 0.33 \\
\hline$>8 \mathrm{~h}$ & 1.09 & $0.49-2.46$ & 0.83 & 1.04 & $0.36-2.98$ & 0.95 & 1.60 & $0.41-6.26$ & 0.50 \\
\hline \multicolumn{10}{|l|}{ Smoking behavior } \\
\hline Nonsmoker & & Ref. & & & Ref. & & & Ref. & \\
\hline Ceased smoker & 0.99 & $0.64-1.51$ & 0.95 & 0.95 & $0.55-1.66$ & 0.87 & 1.00 & $0.46-2.19$ & 1.00 \\
\hline Current smoker & 0.99 & $0.68-1.43$ & 0.94 & 1.03 & $0.64-1.66$ & 0.90 & 1.01 & $0.51-1.99$ & 0.98 \\
\hline \multicolumn{10}{|l|}{ Alcohol consumption } \\
\hline None/rare & & Ref. & & & Ref. & & & Ref. & \\
\hline 1-2/week & 0.75 & $0.50-1.12$ & 0.16 & 0.52 & $0.30-0.91$ & $<0.05$ & 1.08 & $0.58-2.01$ & 0.82 \\
\hline 3-5/week & 0.78 & $0.48-1.27$ & 0.32 & 0.71 & $0.37-1.36$ & 0.30 & 0.92 & $0.43-1.98$ & 0.84 \\
\hline 6-7/week & 0.90 & $0.61-1.34$ & 0.61 & 0.81 & $0.49-1.33$ & 0.41 & 1.05 & $0.49-2.24$ & 0.90 \\
\hline
\end{tabular}

OR: odds ratio; CI: confidence interval; Ref.: reference group to which all other categorical variables are compared (binomial multivariate logistic regression). 
associated with an increased risk of depression. A proportion of employees with high psychological distress possibly work longer hours to keep up with an excessive workload [21]. Further, several studies pointed out an association between insomnia and depression [25, 26]. Moreover, some studies from Japan examined the relationship between depressive symptoms, as assessed using the CES-D, and sleep state $[27,28]$. Another study investigated the relationship between lifestyle, as defined by common health habits like sleeping habits, and symptoms of depression [29].

Many previous studies suggest sleep disturbances as a risk factor for depression. The results of both our 2007 and 2010 studies have shown that short sleep duration was associated with a high risk of depression. Moreover, when sleep duration (per day) was divided by weekdays and holidays, it was found that sleep duration on weekdays might be a useful indicator of depression.

Regarding alcohol consumption, men who consumed alcohol "1-2 days/week" had a relatively low risk to be high scorers on the CES-D compared with those who drank nothing or rarely. In our previous 2007 study [11], "sometimes" consuming alcohol was associated with a higher risk of depression compared with daily consumption. The reason for this trend is unclear; however, it is possible that participants that reported "none/rare" consumption already have a declining health status (i.e., they cannot consume due to their ill health). Further studies are required to clarify this point.

The limitation of this study lies in its cross-sectional design, which makes it difficult to determine whether these correlations between sociodemographic characteristics and depressive symptoms indicate antecedents or consequences of depressive disorders. In order to make inferences with regard to causality, a longitudinal follow-up study will be needed. The present study applied measures for different periods (i.e., the 2010 survey was a follow-up to the 2007 survey) and adopted a similar method to our previous study. From this, it is thought that the distinction between the result which is with the plasticity and the result which is not so is enabled. However, it is necessary to survey participants more than twice to show this thoroughly. While our use of 16 as the cutoff point for depressive disorders was justified by previous studies, this does not specifically indicate a clinical diagnosis of depression [5, 9]. Thus, it is difficult to compare the results of this study with that of other surveys, which used diagnostic approaches. As such, another type of epidemiological survey that applies a standardized diagnostic instrument in addition to a nondiagnostic one will be needed.

\section{Conflict of Interests}

The author declares that there is no conflict of interests regarding the publication of this paper.

\section{Acknowledgments}

The author would like to thank all of the occupational physicians from the seven administrative occupational health promotion centers located in the prefectures of northern
Japan (Hokkaido, Aomori, Iwate, Miyagi, Akita, Yamagata, and Fukushima prefectures) and their assistants for their help during the course of the investigation and also all the operators who contributed to the study.

\section{References}

[1] M. Fushimi, J. Sugawara, and T. Shimizu, "Suicide patterns and characteristics in Akita, Japan," Psychiatry and Clinical Neurosciences, vol. 59, no. 3, pp. 296-302, 2005.

[2] A. Tsutsumi, M. Nagami, T. Yoshikawa, K. Kogi, and N. Kawakami, "Participatory intervention for workplace improvements on mental health and job performance among blue-collar workers: a cluster randomized controlled trial," Journal of Occupational \& Environmental Medicine, vol. 51, no. 5, pp. 554$563,2009$.

[3] R. Umanodan, Y. Kobayashi, M. Nakamura, K. Kitaoka-Higashiguchi, N. Kawakami, and A. Shimazu, "Effects of a worksite stress management training program with six short-hour sessions: a controlled trial among Japanese employees," Journal of Occupational Health, vol. 51, no. 4, pp. 294-302, 2009.

[4] P. S. Wang, G. E. Simon, J. Avorn et al., "Telephone screening, outreach, and care management for depressed workers and impact on clinical and work productivity outcomes: a randomized controlled trial," Journal of the American Medical Association, vol. 298, no. 12, pp. 1401-1411, 2007.

[5] M. J. Cho, J. J. Nam, and G. H. Suh, "Prevalence of symptoms of depression in a nationwide sample of Korean adults," Psychiatry Research, vol. 81, no. 3, pp. 341-352, 1998.

[6] L. Stallones, M. B. Marx, and T. F. Garrity, "Prevalence and correlates of depressive symptoms among older U.S. adults," The American Journal of Preventive Medicine, vol. 6, no. 5, pp. 295303, 1990.

[7] L. S. Radloff, “The CES-D scale: a self-report depression scale for research in the general population," Applied Psychological Measurement, vol. 1, no. 3, pp. 385-401, 1977.

[8] R. E. Roberts and S. W. Vernon, "The center for epidemiologic studies depression scale: its use in a community sample," American Journal of Psychiatry, vol. 140, no. 1, pp. 41-46, 1983.

[9] N. Iwata, Y. Okuyama, Y. Kawakami, and K. Saito, "Prevalence of depressive symptoms in a Japanese occupational setting: a preliminary study," The American Journal of Public Health, vol. 79, no. 11, pp. 1486-1489, 1989.

[10] N. Iwata, M. Umesue, K. Egashira et al., "Can positive affect items be used to assess depressive disorders in the Japanese population?" Psychological Medicine, vol. 28, no. 1, pp. 153-158, 1998.

[11] M. Fushimi, S. Saito, and T. Shimizu, "Prevalence of depressive symptoms and related factors in Japanese employees as measured by the center for epidemiologic studies depression scale (CES-D)," Community Mental Health Journal, vol. 49, no. 2, pp. 236-242, 2013.

[12] G. E. Barnes, R. F. Currie, and A. Segall, "Symptoms of depression in a Canadian urban sample," Canadian Journal of Psychiatry, vol. 33, no. 5, pp. 386-393, 1988.

[13] Y.-W. Ying, "Depressive symptomatology among ChineseAmericans as measured by the CES-D," Journal of Clinical Psychology, vol. 44, no. 5, pp. 739-746, 1988.

[14] J. W. Williams Jr., M. Gerrity, T. Holsinger, S. Dobscha, B. Gaynes, and A. Dietrich, "Systematic review of multifaceted interventions to improve depression care," General Hospital Psychiatry, vol. 29, no. 2, pp. 91-116, 2007. 
[15] M. Fushimi, “The relationship between individual personality traits (internality-externality) and psychological distress in employees in Japan," Depression Research and Treatment, vol. 2011, Article ID 731307, 6 pages, 2011.

[16] M. Fushimi, S. Saito, T. Shimizu, Y. Kudo, M. Seki, and K. Murata, "Prevalence of psychological distress, as measured by the kessler 6 (K6), and related factors in Japanese employees," Community Mental Health Journal, vol. 48, no. 3, pp. 328-335, 2012.

[17] G. W. Comstock and K. J. Helsing, "Symptoms of depression in two communities," Psychological Medicine, vol. 6, no. 4, pp. 551$563,1976$.

[18] B. A. Husaini, J. A. Neff, J. B. Harrington, M. D. Houghs, and R. H. Stone, "Depression in rural communities: validating the CES-D scale," Journal of Community Psychology, vol. 8, no. 1, pp. 20-27, 1980.

[19] M. G. Madianos, V. Tomaras, A. Kapsali, N. Vaidakis, J. Vlachonicolis, and C. N. Stefanis, "Psychiatric case identification in two Athenian communities: estimation of the probable prevalence," Acta Psychiatrica Scandinavica, vol. 78, no. 1, pp. 24-31, 1988.

[20] W. E. Narrow, D. S. Rae, E. K. Moscicki, B. Z. Locke, and D. A. Regier, "Depression among Cuban Americans: the Hispanic Health and Nutrition Examination Survey," Social Psychiatry and Psychiatric Epidemiology, vol. 25, no. 5, pp. 260-268, 1990.

[21] M. F. Hilton, H. A. Whiteford, J. S. Sheridan et al., "The prevalence of psychological distress in employees and associated occupational risk factors," Journal of Occupational and Environmental Medicine, vol. 50, no. 7, pp. 746-757, 2008.

[22] M. Fushimi, T. Shimizu, S. Saito, Y. Kudo, M. Seki, and K. Murata, "Prevalence of and risk factors for psychological distress among employees in Japan," Public Health, vol. 124, no. 12, pp. 713-715, 2010.

[23] R. M. D’Souza, L. Strazdins, D. H. Broom, B. Rodgers, and H. L. Berry, "Work demands, job insecurity and sickness absence from work. How productive is the new, flexible labour force?" Australian and New Zealand Journal of Public Health, vol. 30, no. 3, pp. 205-212, 2006.

[24] S. A. Stansfeld, R. Fuhrer, M. J. Shipley, and M. G. Marmot, "Work characteristics predict psychiatric disorder: prospective results from the Whitehall II study," Occupational and Environmental Medicine, vol. 56, no. 5, pp. 302-307, 1999.

[25] P. P. Chang, D. E. Ford, L. A. Mead, L. Cooper-Patrick, and M. J. Klag, "Insomnia in young men and subsequent depression. The Johns Hopkins Precursors Study," The American Journal of Epidemiology, vol. 146, no. 2, pp. 105-114, 1997.

[26] D. Riemann and U. Voderholzer, "Primary insomnia: a risk factor to develop depression?" Journal of Affective Disorders, vol. 76, no. 1-3, pp. 255-259, 2003.

[27] Y. Kaneita, T. Ohida, M. Uchiyama et al., "The relationship between depression and sleep disturbances: a Japanese nationwide general population survey," Journal of Clinical Psychiatry, vol. 67, no. 2, pp. 196-203, 2006.

[28] A. Nakata, T. Haratani, M. Takahashi et al., "Association of sickness absence with poor sleep and depressive symptoms in shift workers," Chronobiology International, vol. 21, no. 6, pp. 899-912, 2004.

[29] T. Frederick, R. R. Frerichs, and V. A. Clark, "Personal health habits and symptoms of depression at the community level," Preventive Medicine, vol. 17, no. 2, pp. 173-182, 1988. 


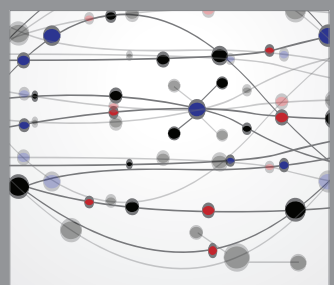

The Scientific World Journal
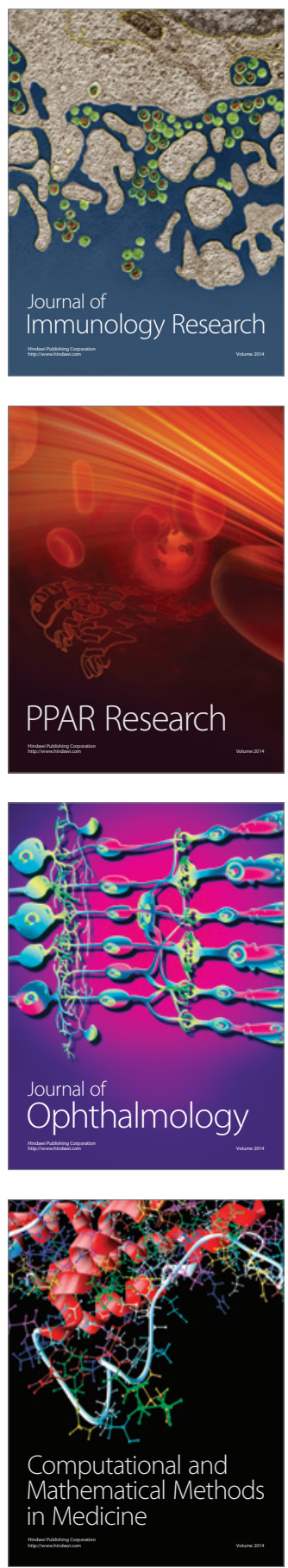

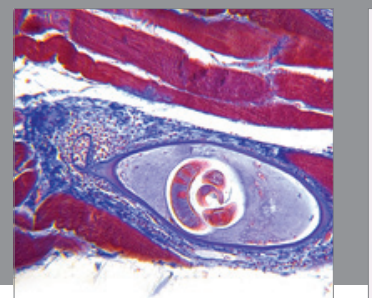

Gastroenterology

Research and Practice
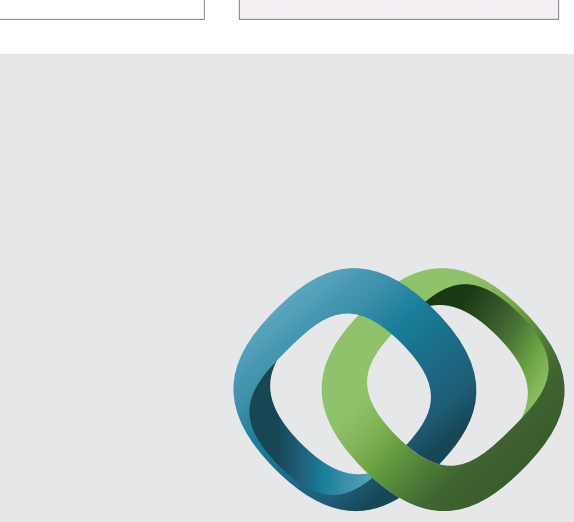

\section{Hindawi}

Submit your manuscripts at

http://www.hindawi.com
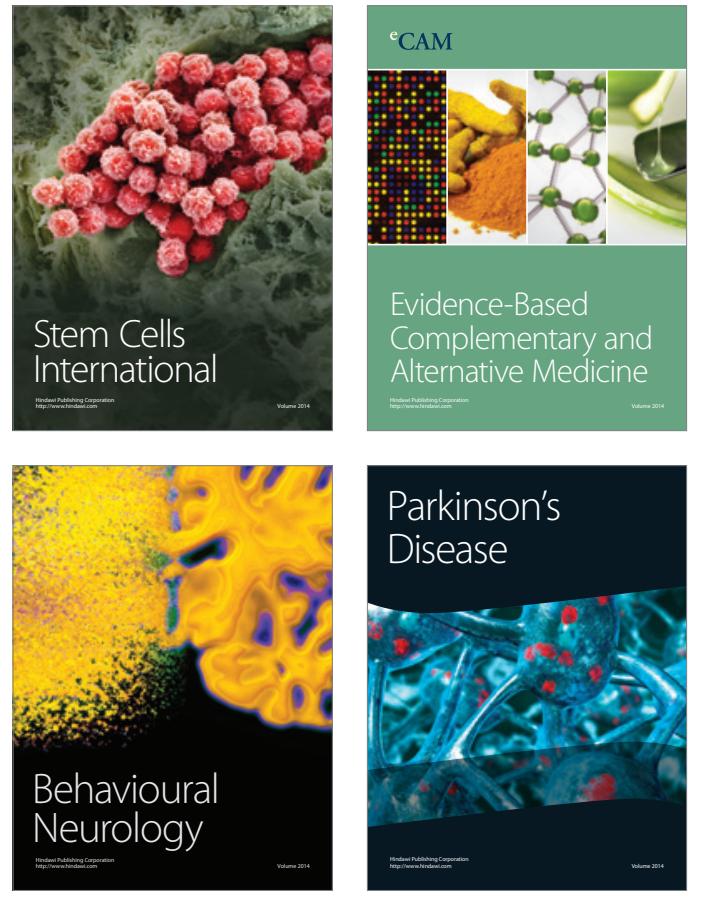
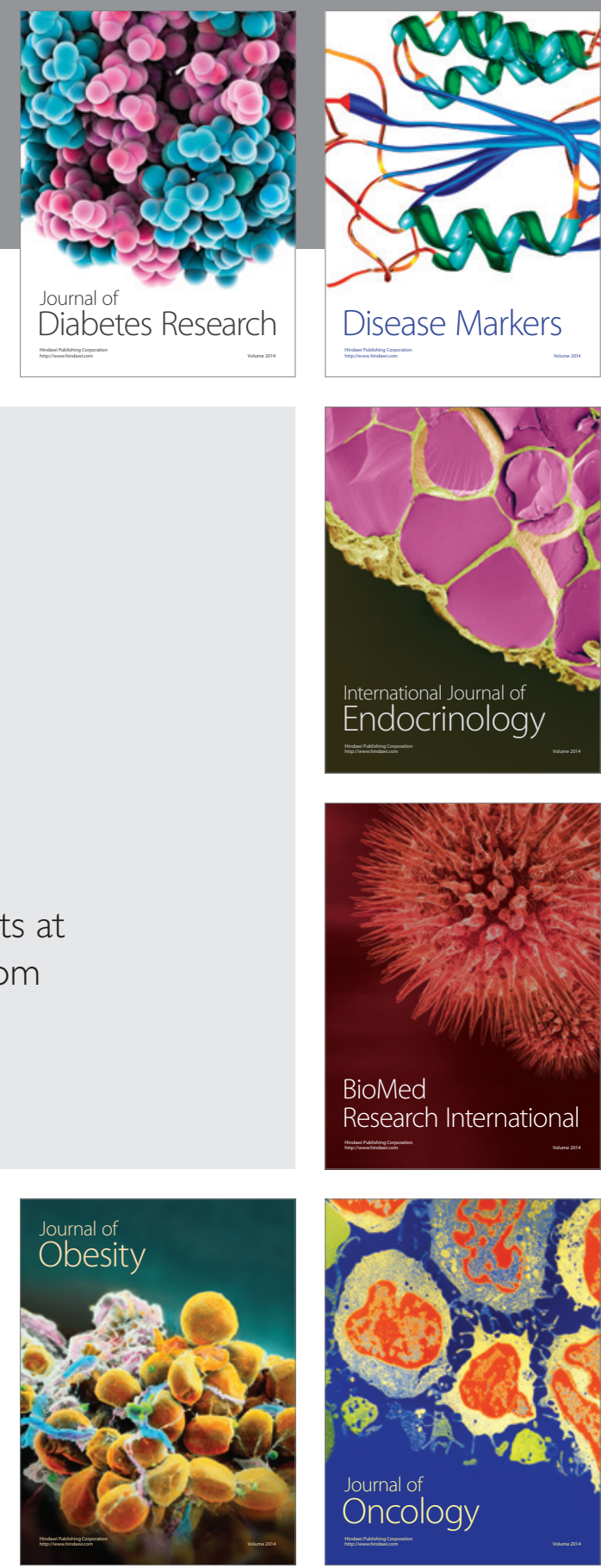

Disease Markers
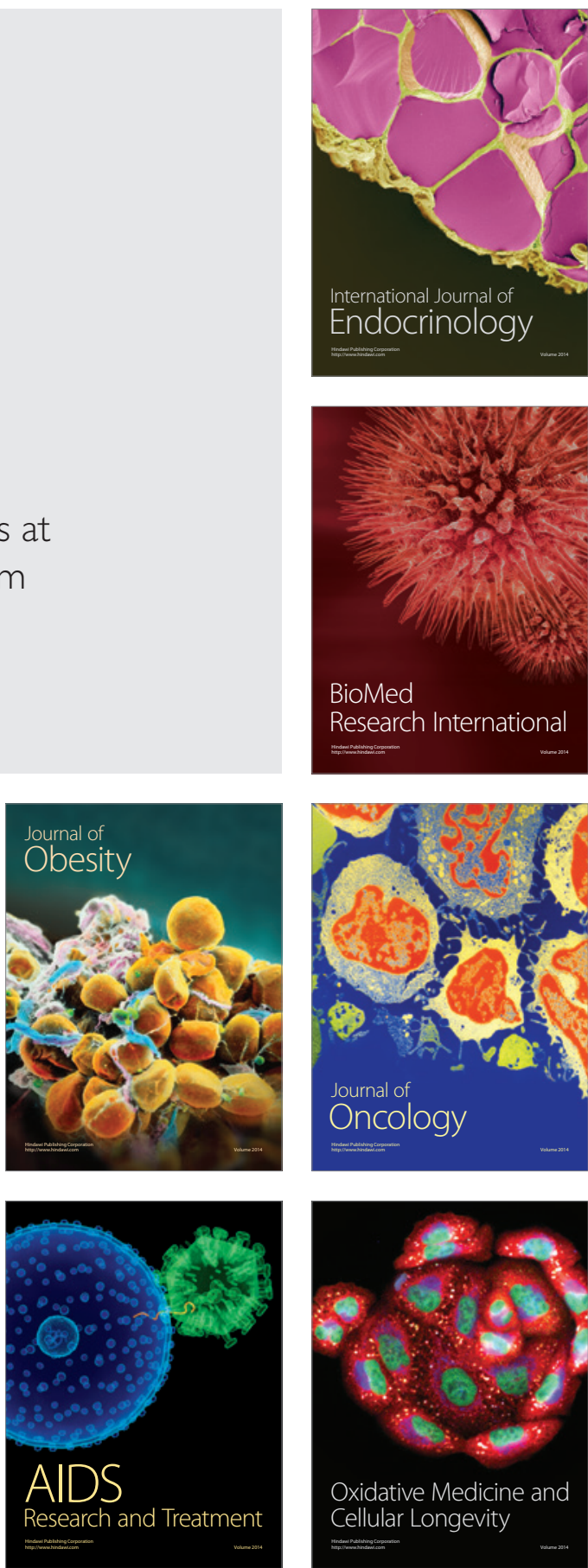